\title{
E ONDE FICA ADÃO NESTA HISTÓRIA?! DO DESAFIO DE ENSINAR HISTÓRIA DIANTE DO FUNDAMENTALISMO RELIGIOSO
}

Ademir Luiz da Silval

RESUMO: Neste artigo procuro discutir de que forma o fundamentalismo religioso reinante em nossa sociedade tende a minar, ou no mínimo censurar, o ensino de História, quando a ciência histórica coloca em xeque algum dogma de sua tradição.

PALAVRAS-CHAVE: Fundamentalismo, História, Religião.

SO, WHERE IS ADAM IN THIS STORY? THE CHALLENGE OF TEACHING HISTORY IN THE FACE OF THE RELIGIOUS FUNDAMENTALISM

In this article I try to debate on the form of religious fundamentalism prevailing in our society, which tries to undermine, or at least to censor the teaching of history, while the historical science questions some principles of its tradition.

KEY WORDS: Fundamentalism, History, Religion.

\section{O EVOLUCIONISMO COMO UMA MENTIRA COMPROVA- DA CIENTIFICAMENTE}

É incontestável que a doutrina de um Deus pessoal que interfere com acontecimentos naturais nunca pode ser refutada, no sentido real do termo, pela Ciência, pois essa doutrina sempre se pode refugiar naqueles domínios em que o conhecimento científico ainda não foi capaz de se afirmar.

(Albert Einstein)

1. Professor substituto de História, no Cepae/UFG, e mestrando em História das Sociedades Agrárias/UFG. 
Todo professor de História vive um dilema anual: como apresentar a matéria sobre o surgimento do homem sem ofender a gregos ou a troianos?

A escola é, ou deveria ser, uma instituição laica por definição. Muito mais do que uma difusora de ideologias, ela tem o dever e a vocação de ser uma difusora do saber, isenta de qualquer tipo de preconceito. Um livro didático nada mais é do que o substrato do conhecimento humano acumulado em anos, décadas, ou mesmo séculos, de estudos teóricos e empíricos realizados por incontáveis cientistas e homens de letras; alguns gênios, outros nem tanto, mas todos humanos, muito humanos, lidando com problemas tipicamente humanos. O que se publica para fins didáticos é tão-somente o resultado do provado e comprovado por esses esforços. Senão vejamos: em um livro de Química não existe lugar para o éter olímpico. Em um livro de Física o que se vê é matemática aplicada, puramente lógica, nunca teorias mirabolantes seguidas de explicações herméticas. Os livros de Biologia fazem questão de trazer fotografias ampliadas de seres microscópicos para que não se tenha dúvidas de que eles realmente existem. Os livros de Geografia sabiamente fazem o mesmo com os planetas e as galáxias, provando que de fato há muito mais espaço aí fora do que Horácio poderia imaginar. Tudo isso é líquido e certo, óbvio até. Ninguém se atreve a duvidar das informações contidas nesses receptáculos de conhecimento que são esses livros didáticos. Seus digníssimos autores são pessoas acima de qualquer suspeita diante do aluno, seu discípulo, usuário de cornucópia das verdades indiscutíveis que são suas obras; grandes e volumosas obras na maioria das vezes. Não por acaso, na aparência, estas guardam semelhanças com outros livros igualmente sagrados de natureza, digamos, mais transcendentes.

Não obstante isso, os autores de livros didáticos de História são quase sempre taxados pelos alunos de charlatões, hereges e o pior de tudo: chatos de galocha. Tudo isso porque, por força do ofício, tocam nas feridas abertas daquilo que o ser humano possui de mais característico e ao mesmo tempo mais incerto: sua fé. Diversas foram as vezes em que ouvi um aluno resmungar diante de um texto ou prova de História: "Não acredito em nada disto. Estudo porque tenho de estudar, mas não está escrito nas escrituras." 
Os alvos da negação são os mais variados. Exemplos não faltam. Na Idade Antiga poucos aceitam que o paganismo hedonista das sociedades clássicas não se tratava de pura sem-vergonhice e sim de hábitos culturais de povos que não conheciam a idéia oriental de pecado; mero "sentimento de escravos" (Nietzsche, 1989, p.108), como diria um grego. Na Idade Média parece haver uma enorme resistência mental em relacionar a Igreja que perpetrou as monstruosidades da Inquisição e a chacina das Cruzadas com a "justíssima" instituição que se conhece hoje. Na Idade Moderna muitos evitam sequer pensar nas origens muito mais econômicas do que propriamente espirituais da Reforma Protestante, achando impossível que o novo patriarca Lutero pudesse prestar-se a este papel. Na Idade Contemporânea recebem o golpe final quando se deparam com o mais polêmico, escorregadio, e ao mesmo tempo inevitável, de todos os temas: a origem do homem posta a nu pela ciência materialista do século XIX.

Nesse ponto o historiador torna-se definitivamente um mentiroso. Como pode ter o desplante de afirmar que o homem veio de um macaco, que por sua vez veio de um mamífero minúsculo com jeito de roedor, que veio de um peixe, que veio de uma célula original, que ninguém sabe ao certo de onde veio?! Pouco adianta explicar que nós não "viemos" e sim evoluímos; e que não se tratava de macacos, mas de antropóides superiores. A experiência mostra que neste instante a maior parte dos alunos estará se perguntando: "e onde fica Adão nesta história?!"

Eles estão certos. Esta questão deve mesmo ser formulada: e onde fica Adão nesta história?

Em minha opinião, Adão deve ficar em seu honroso lugar de direito: a tradição. As convicções religiosas pessoais precisam ser respeitadas. Porém, jamais, em hipótese alguma, devem tomar o lugar da ciência; responder as questões que cabe à ciência responder. Infelizmente não é isso o que acontece. A verdade é que o mito da criação divina do homem e do universo é um dos últimos grandes tabus a sobreviver no imaginário popular de nossa época. Há tempos que a Terra deixou de ser quadrada. Ninguém mais acredita em concepção via cegonha ou tem dúvidas de que o Papai Noel é uma invenção da Coca-Cola. Da mesma forma ninguém, por mais bronco 
que seja, por mais que se alardeie o contrário, duvida do fato de que Armstrong pisou na lua. Até a suprema tolice do nazismo é proibida por lei em várias partes do mundo. O racionalismo parece imperar na sociedade moderna. Ledo engano. A coisa muda de figura quando se pergunta para alguém como surgiu o homem. É quase certo que nove entre dez pessoas incluiriam em sua resposta as palavras barro e costela.

A hegemonia do mito sobre a verdade científica não é por acaso. Conta-se que em 1860, pouco depois da publicação de A origem das espécies, de Charles Darwin, a esposa do bispo de Worcester exclamou preocupada: "Barbaridade, descendemos de macacos! Esperemos que não seja verdade, mas se for rezemos para que isto não venha a se tornar amplamente conhecido." (Leakley \& Lewin, 1982, p. 21)

Não é necessário explicar que a preocupação da nobre beata inglesa era a sobrevivência das regras sociais, da moral e dos bons costumes, que certamente estariam ameaçados diante de uma revelação tão "bestial" como aquela. Provavelmente estaria pensando a beata, tomando liberdades com a frase célebre de Dostoievski: "se somos macacos tudo é permitido."

Felizmente para a digníssima senhora inglesa o planeta dos homens continuou o mesmo. Não mergulhou no caos símio. As idéias de Darwin, apesar do impacto inicial, não se tornaram muito conhecidas, e aceitas, fora dos círculos acadêmicos. Nesse aspecto perderam de longe em popularidade para as contemporâneas idéias de Sigmund Freud, que hoje fazem parte do cotidiano de todos nós. Basta atentar para o uso corrente de termos da psicanálise, tais como neurótico, psicótico, histérico etc. Esse fenômeno de obscuridade tem um significado profundo. $\mathrm{O}$ ser humano pode até admitir que "nem mesmo em sua própria casa é ele quem dá as ordens, mas que deve contentar-se com as escassas informações do que se passa inconscientemente em sua mente" (Freud, 1986, p. 59), mas não aceita de forma alguma perder sua descendência divina. Não admite ser órfão. O resultado é que refuta toda e qualquer tentativa de colocá-lo em seu devido lugar no âmbito da criação: o de um animal fraco, 
lento, pouco ágil, de parca visão; porém dotado de extrema habilidade manual e criatividade.

Quem paga a conta dessa omissão é a ciência de modo geral e a didática histórica em particular. Claro que hoje, passados os tempos negros da Inquisição, ninguém mais é queimado vivo, mas, ainda assim, muitas vezes o combate às idéias religiosamente rebeldes é explícito. O caso recente do escritor lusitano José Saramago é sintomático. Seu romance $O$ Evangelho Segundo Jesus Cristo foi proibido pelo Estado de Cultura de representar Portugal no Prêmio Literário Europeu, em 1992, sob a alegação de que ofendia as convicções religiosas do povo português. Tudo porque Saramago, um ateu convicto e confesso, retratou em seu livro um Jesus de Nazaré muito mais humano do que divino. Ofendido, o escritor resolveu se exilar nas Ilhas Canárias. Não pretendia ser um novo Kazantzakis, o autor do romance A Última Tentação de Cristo, que chegou a ser excomungado pela Igreja Ortodoxa Grega.

É comum acusar as igrejas cristãs de intolerância, mas essa prática vem de antes de Cristo. Lembro-me de que uma das acusações que pesava sobre Sócrates, no julgamento que acabou resultando em sua condenação à morte, foi a de ser ateu e corromper os jovens atenienses, "ensinando-os a não acreditar nos deuses em que a cidade [acreditava]" (Platão, 1999, p. 77). Nada mais falso, como demonstrou Platão em sua "Apologia a Sócrates". O filósofo apenas colocava a tradição em seu devido lugar, submetida ao logos, à razão. De qualquer forma, mesmo inocente, Sócrates bebeu cicuta, obedecendo à vontade democrática dos cidadãos de Atenas, que votaram pela eliminação de sua presença intelectualmente perigosa.

Se soa estranho esse escabroso erro jurídico no seio da festejada democracia grega, espanta ainda mais acontecer algo semelhante em nossos dias na "pátria da liberdade de expressão". No final dos anos noventa foi divulgado no Brasil que grupos religiosos cristãos fundamentalistas norte-americanos simplesmente proibiram o ensino do evolucionismo em certas escolas dos Estados Unidos. A justificativa não poderia ser mais risível. Os fanáticos alegavam que as teorias de Darwin afastavam as crianças da "verdade". O que temos aqui é o mais claro exemplo de inversão de valores: dogma tornou-se sinônimo de verdade. Mas os dogmas, como se sabe, são variáveis 
de cultura para cultura. Pensemos. Se acontecesse o mesmo na Índia, por exemplo, não se estaria sacrificando o evolucionismo em prol do Fiat Lux, e sim do Dia e da Noite de Brahma. Podemos ir ainda mais longe no raciocínio. E se acaso uma criança hindu estivesse estudando em uma destas escolas norte-americanas? Seus pais poderiam protestar pelo fato de os professores do tal estabelecimento de ensino estarem ensinando "mentiras" a seu filho? Tratando-se de Estados Unidos podemos estar diante de uma ação judicial de milhões de dólares.

Em meio a este cenário burlesco, uma coisa é certa: se existe algo que pode aproximar o homem de algum tipo de verdade, esse algo é a ciência. Em 1996 o próprio Vaticano, na figura do Papa João Paulo II, admitiu, ainda que timidamente, como aliás é de seu feitio, que a teoria da evolução natural "é algo mais do que uma hipótese" e que "a ciência pode purificar a religião do erro e da superstição". Nada mais justo, sobretudo quando lembramos que o difamado Darwin, o pivô da polêmica, era cristão e chegou a declarar que "não via nenhum motivo para que as idéias expostas em seu livro chocassem as crenças religiosas de quem quer que fossem" (Darwin, 1986, p. 77). Einstein, seu colega de labuta cientista, poderia consolá-lo pela absolvição tardia, dizendo-lhe que

a razão é fraca naturalmente, quando confrontada com sua tarefa infindável. Fraca realmente, se comparada às loucuras e paixões da humanidade, as quais, temos de admitir, quase inteiramente controlam o nosso destino humano, nas grandes e nas pequenas coisas. No entanto, a obra do entendimento sobrevive às gerações barulhentas e obstrutivas e espalha luz e calor através dos séculos. (Einstein, 1986, p. 87)

De qualquer forma, levando-se em conta que a maior parte da humanidade é incapaz de viver sem crenças no transcendente, como provou a fracassada experiência de ateísmo forçado na Rússia pósrevolução, o bom senso exige que ao menos se separem o máximo possível os termos: o templo, independente da religião, é para oração; a escola é para aprender ciência, lógica. No templo, água pode 
até transformar-se em vinho; na escola, em hipótese alguma, água e óleo devem se misturar.

\section{O EVOLUCIONISMO POSTO NA FOGUEIRA}

Tendo em mente o que escrevi acima decidi levar tal problema para a sala de aula, aqui no Centro de Pesquisa Aplicada à Educação da Universidade Federal de Goiás, em duas turmas de primeiro ano do ensino médio, durante o mês de março de 2001, aproveitando o ensejo anual a que me referi no início deste artigo: o momento em que se deve tratar do surgimento do homem.

Após a leitura em sala do capítulo do livro didático relativo a essa questão, propus um exercício: a produção de um texto em que o aluno deveria expor sua opinião pessoal acerca das duas explicações para a origem do homem, a científica e a tradicional. No enunciado fiz questão de deixar claro: "não basta escrever que acredita no evolucionismo ou no criacionismo. Pesquise o tema antes de escrever. Desenvolva uma argumentação embasada, explicando as razões de sua crença em uma ou em outra opção teórica. Exercite seu poder de argumentação e lembre-se de que o mais importante neste trabalho não é sua opinião e sim o quanto você foi convincente defendendo-a". Os alunos tiveram uma semana para preparar o texto pedido.

Selecionei alguns trechos de trabalhos. A transcrição é fiel às versões manuscritas.

(1) Eu, particularmente, acho um absurdo o que o cientista inglês Charles Darwin escreveu em seu livro A Origem das Espécies.

(2) Bem, eu acho que essa coisa que dizem sobre o homem ter nascido do macaco é uma tremenda bobagem, pois se isso fosse verdade não existiriam mais macacos, pois todos iriam se transformar em homens, e isso não acontece. [...] Os cientistas gostam de fazer afirmações, porque encontram ossadas de qualquer coisa e dizem que são ossadas humanas.

(3) Eu acredito que o homem foi criado por Deus e está para mim fora de cogitação a idéia de que o homem surgiu do macaco, isto para mim é conversa pra boi dormir e só para ter mais o que estudar nas escolas ou melhor dizendo nas aulas de História. 
(4) Esta é a origem do homem que eu acredito, porque está é a palavra de Deus e tudo o que neste livro sagrado está escrito irá acontecer, imbecil é aquele que não acredita na palavra de Deus e zomba dela, este será condenado e queimará eternamente no lago de fogo.

(5) Na minha opinião eu acredito mais na história do evolucionismo, não porque não acredito na estória da criação divina, mas acho que a teoria da evolução tem mais sentido.

(6) Não que eu não seja religioso (não tanto quanto deveria) mas é que acho que o evolucionismo é tão mais óbvio que o criacionismo, e, além do mais, prefiro sacanear esses padres que se acham o centro do universo como classificam a Terra.

(7) Eu acho que elas duas juntas que deram origem ao seres vivos.

(8) No Brasil o evolucionismo não é aceito, porque nós vivemos em um país regido por várias crenças religiosas, e dão várias definições sobre o surgimento dos seres vivos. Por isto esse assunto causa tanta polêmica até hoje onde uma grande parte da população é instruída.Então a partir do momento que eu adoto o evolucionismo, eu perco todo aquele pensamento religioso e passo a ser um (ateu) e é esse o medo das pessoas.

(9) Esse Deus não é melhor: essa força suprema pode até existir, todavia as igrejas fazem uso dela como mais uma instituição humana para dominar pensamentos, alienar pessoas. O que há de mau em saber que temos um elo em comum com os primatas? Se muitas vezes somos tão irracionais e inconseqüentes quanto os bichos!

Em virtude do parco espaço de que disponho tecerei apenas um breve comentário acerca dos trechos apresentados. Grosso modo, pode-se perceber um óbvio estado de confusão mental na maior parte dos trabalhos. Os conceitos básicos da teoria da seleção natural, apesar de meus esforços didáticos, não parecem claros para todos. 
Os primeiros (1, 2, 3 e 4) negam totalmente as evidências científicas, acusando-as de serem meras elucubrações alucinógenas dos pesquisadores e professores que as divulgam. Notem que o segundo texto possui a ingenuidade quase cômica de afirmar que qualquer osso de galinha, encontrável em qualquer cesta de lixo, pode ser confundido com um fóssil; além de, clássico dos clássicos, identificar os símios atuais com a linha evolutiva dos antropóides superiores. Digna de nota é a pregação fundamentalista esboçada no quarto texto. $\mathrm{O}$ estudante que o compôs conclama todos os materialistas à conversão imediata, sob pena de sofrerem punição divina caso insistam em manter suas condutas pecaminosas: não condizentes com a tradição. É de fato muito comum escutarmos crentes ameaçando descrentes com algum tipo de fogo infernal, dizendo-lhes que vão "pagar por não aceitar a verdade", como se esta verdade não fosse acima de tudo um dogma: que, como já vimos, é variável.

A partir do texto número 5 encontramos um tipo peculiar de conduta. $\mathrm{O}$ aluno percebe a lógica irrefutável do evolucionismo, e não pode negá-la, ao mesmo tempo em que procura se prender escrupulosamente à explicação divina. $\mathrm{O}$ que parece existir é um certo sentimento de culpa em abandoná-la, como se percebe no sexto fragmento, quando seu autor afirma entre parênteses que não é tão religioso "quanto deveria". Mesmo se mostrando insatisfeito com a conduta dos sacerdotes de sua religião, recusa-se a negá-la, o que prova que a força da idéia é muito mais poderosa do que qualquer insatisfação que porventura possa existir em função do cotidiano da prática religiosa. O resultado é uma tentativa de unir ambas as teorias, como forma de purgação, desencargo de consciência, objetivo explicitado no texto número 7. A impossibilidade prática de realizar tal façanha teórica não impede o aluno de apegar-se a essa improvável solução.

Os textos 8 e 9 mostram uma visão mais crítica ao analisar o problema, o que faz de ambos exceções no universo de trabalhos recolhidos.

O oitavo texto lembra-nos de que a dificuldade da comunidade em aceitar a verdade indiscutível do evolucionismo se deve ao fato de que é a religião que rege os valores sociais de nosso país. E isso realmente se confirma na trindade "família, tradição e propriedade". Qualquer postura contrária a essa receita é malvista social- 
mente. Isso implica que ser um materialista, um ateu, é cometer "pecado", o que por si só é uma contradição, já que o indivíduo que não crê não pode ser incorporado aos princípios da crença. Conviver com esse "pecador", ou pior, tornar-se como ele é o "medo das pessoas", pois isso significaria compartilhar do mesmo ar com alguém que, tendo desafiado a ordem estabelecida, já está, segundo a tradição, previamente condenado em vida. É um embaraço ambulante, um ser estranho, um pária enfim.

O texto número 9 trata da questão do uso ideológico, alienante, da tradição, que é, afinal de contas, uma invenção tão humana quanto a política e segue, a bem da verdade, os mesmos preceitos. Seu autor termina a reflexão aceitando de bom grado o parentesco com os símios, lembrando que muitas vezes somos tão irracionais, emotivos e incontroláveis quanto eles. Tanta semelhança só pode mesmo sugerir parentesco. O que não surpreende, considerando que todos nós, homens civilizados, temos em nosso círculo familiar mais íntimo ao menos um exemplar da numerosa raça dos primos chatos, mentirosos, preguiçosos e inconvenientes. Chega a ser um alívio compará-lo a um chimpanzé.

\section{REFERÊNCIAS}

DARWIN, C. O pensamento vivo de Darwin. São Paulo: Martin Claret, 1986.

EINSTEIN, A. O pensamento vivo de Einstein. São Paulo: Martin Claret, 1986.

FREUD, Sigmund. O pensamento vivo de Freud. São Paulo: Martin Claret, 1986.

GAARDEN, J. O mundo de Sofia: romance da história da filosofia. São Paulo: Companhia das Letras, 1997.

LEAKLEY, R. E., LEWIN, R. Origens. 4. ed. São Paulo: Melhoramentos, 1982.

NIETZSCHE, F. A gaia ciência. São Paulo: Ediouro, 1989. 
PLATÃO. Apologia a Sócrates. Platão. São Paulo: Nova Cultural, 1999. (Col. Os Pensadores).

SARAMAGO, J. O evangelho segundo Jesus Cristo. Rio de Janeiro: Record, 1996. 